\title{
Typical Errors and Solving Strategies in Biology Test in College Entrance Examination
}

\author{
Shao Danwei ${ }^{1, ~ *}$, Lin Yu ${ }^{1,2}$ \\ ${ }^{1}$ Senior High School, Ningbo Binhai International Cooperative School, Ningbo, China \\ ${ }^{2}$ Science Experimental Class, Institute of Science and Technology, Chinese University of Hong Kong, Shenzhen, China \\ Email address: \\ sdw661133@163.com (Shao Danwei), 1543876931@qq.com (Lin Yu) \\ ${ }^{*}$ Corresponding author
}

To cite this article:

Shao Danwei, Lin Yu. Typical Errors and Solving Strategies in Biology Test in College Entrance Examination. Education Journal. Vol. 8, No. 6, 2019, pp. 327-331. doi: 10.11648/j.edu.20190806.23

Received: October 20, 2019; Accepted: November 18, 2019; Published: November 27, 2019

\begin{abstract}
Errors are inevitable by-products of learning. Resource utilization of errors was to turn this raw material into the education resource. We transformed them by the observation, analysis, discussion, exploration and some other activities among teachers and students. However, according to the current papers concerning this field, we did have many problems. This essay gathered big data of 2228 students who took simulative biology exam in the New College Entrance Examination in March 2017, organized by Ningbo Education Bureau. This essay try to accurately analyze, classify and locate all kinds of errors made by students, and put forward relevant methods and strategies dealing with different types of errors. Mainly analyzing the scores and typical errors, this essay divided the common errors students made in biology exam into three types: reviewing errors, knowledge errors and thinking errors. And the knowledge errors were divided into conceptual errors, applicatory errors and inquiry errors. Aiming at these three error types as well as group errors, this essay put forward relevant solutions. Teachers should judge, screen, sort out and refine these errors tactfully, and make efforts to design targeted and tailored solutions. Students may make a variety of mistakes of diverse types or natures; therefore, teachers should deal with them with different priorities and methods.
\end{abstract}

Keywords: High School Biology, Types of Errors, Solving Strategies

\section{Introduction}

Errors are inevitable by-products of learning. Austrian philosopher Karl Raimund Popper once said: "The discoveries and creativeness which is richer than correctness are always stimulated from errors." [1] Resource utilization of errors was to turn this raw material into the education resource. We transformed them by the observation, analysis, discussion, exploration and some other activities among teachers and students.

With the new curriculum reform, we paid more and more attention to the development and utilization of curriculum resources [2, 3]. Many teachers begun to attach importance to resources utilization of errors and took advantage of it in practical teaching [4-6]. However, according to the current papers concerning this field, we did have many problems. Firstly, the research of errors utilization did not deeply enough in China. There were few studies given by experts or scholars.
Most of the relevant articles were written by front-line teachers, which contained only biased teaching experience. Secondly, theoretical statements were significantly fewer than case lists. We are also in lack of deep and detailed theoretical analysis and research on the effective utilization of errors. We were also in lack of deep and detailed theoretical analysis and research on the effective utilization of errors. Many research results were only specific conclusions based on individual cases, showing fragmentation, without systematic study and thorough investigation [7].

This essay gathered and tended to big data of 2228 students who took simulative biology exam in the New College Entrance Examination in March 2017, organized by Ningbo Education Bureau. This essay try to accurately analyze, classify and locate all kinds of errors made by students, and put forward relevant methods and strategies dealing with different types of errors. 


\section{Analysis of the Overall Exam Questions and Student Scores}

\subsection{Analysis of the Whole Situation of the Simulative Biology Exam Questions in Ningbo College Entrance Examination of March, 2017}

The exam questions were based on «the experimental textbook of high school curriculum standards», complied with the requirements of "Zhejiang Province general high school academic level examination and college entrance examination standards". Accomodating both the characteristics of college entrance examination and the actual situation of high school biology teaching, the simulative biological college entrance examination of Ningbo evaluated students' knowledge and abilities of biology in a scientific and impartial way. For example, question 7 takes cyanobacteria as the background to investigate the correlation and consistency of cell morphology, structure and function [8].

The knowledge points in both compulsory and elective parts in this test were distributed comprehensively and reasonably. Test design was on the basis of the fundamental biological knowledge. It tested whether students have accurate understanding of the main knowledge of biology and ability to analyze and judge biological phenomena and experiments in a scientific and real situation. The overall guidance of this test was conducive to the implementation of quality education and cultivation of the core quality of biological subjects in ordinary teaching [9].

\subsection{The Overall Situation of the Students and Their Scores in the Simulative Biological College Entrance Examination of NINGBO}

The big data used in this essay was gathered from 2228 student who attended the simulative biological college entrance examination organized by local Education Bureau in Ningbo in March 2017. This fact made it easier to reflect more clearly and comprehensively the types of errors that students at different levels and schools may make. The 2,228 students were from different types of schools: there were provincial level 1 and level 2 Characteristic Demonstration high schools and ordinary high schools; there were both public schools and private schools; there were century-old schools with long histories and new schools with shorter ones.

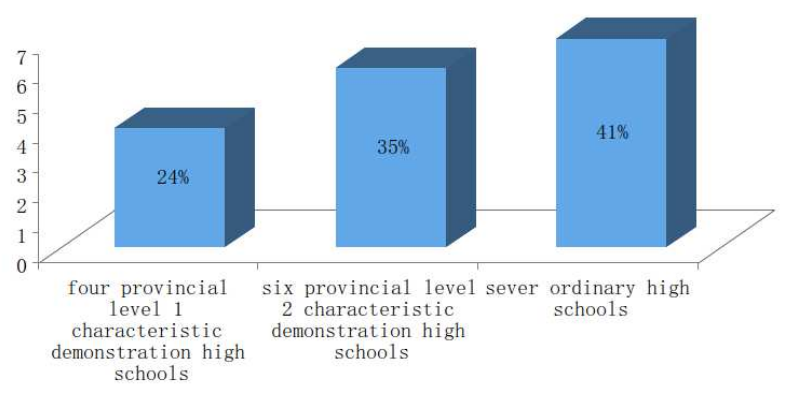

Figure 1. The 2,228 students were from different types of schools.
The total score of this test was 100, including the compulsory 70 points and 30 extra points. According to the statistics of 2228 students, the average score of this test was 60.38, the highest score 94 and the lowest score 5. The original scores basically conformed to the normal distribution law. The standard deviation was 13.45, the difficulty coefficient 0.60 , and the degree of differentiation 0.20 . The final grading standard was determined according to the overall examination results: the score within the scope of 30-31 was assigned to the 21 st grade, and the corresponding score was 40 points. In similar way, the score of 89.3 and above was to the 1 st grade, and the corresponding score was 100 points.

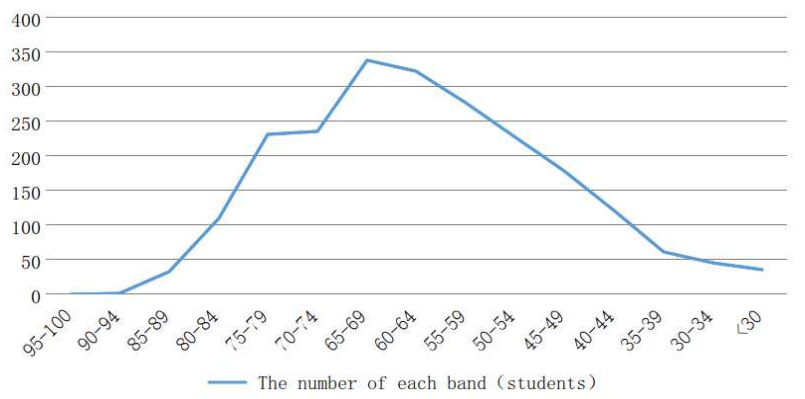

Figure 2. The original scores basically conformed to the normal distribution law.

\section{Error Classification and Analysis of Typical Examples}

The more specific and detailed the teacher's analysis of the errors was, the stronger their ability to harness the error resource and on-the-spot control willed be, and thus the better the effect of errors utilization willed become. At present, many large-scale joint examinations had access to the computer-based analysis of students' answers. If not, it was recommended that teachers should make a statistical analysis of the errors of your students. This essay classified and described typical errors of high school biology in the simulative biological college entrance examination of Ningbo.

\subsection{Reviewing Errors and Case Analysis}

Reviewing the topic was the first step for students to apply the biological knowledge they had learned to solving the problems. However, some students may make mistakes in this very first step of reviewing the questions due to their haste in completing the questions, distortion in extracting the main information, insufficient exploration of the hidden conditions, and falling into the trap of interfering options [10], which eventually led to the loss of scores. For example, question 14 asked test takers to, by analyzing "a couple with normal phenotype gave birth to a hemophiliacs child with $X^{\mathrm{h}} \mathrm{X}^{\mathrm{h}} \mathrm{Y}$ genotype", select the chromosome map of gonium most likely to produce the abnormal gamete. As a result, more students chose the picture of $\mathrm{X}^{\mathrm{h}} \mathrm{X}^{\mathrm{h}}$ incorrectly, which was closely related to the fact that they did not see clearly the two limitations of "normal phenotype couples" and "gonium". 


\subsection{Knowledge Errors and Case Analysis}

The biology examination was designed to evaluate students' basic knowledge of facts, concepts, principles, rules and models of biology; main development direction and achievement of biological science and technology; important events in the history of biological science; the application of biological science knowledge in life, production, scientific and technological development and environmental protection [11]. The students' lack of knowledge in biology was the main cause of their mistakes. Knowledge errors could be further divided into several subtypes:

\subsubsection{Conceptual Errors and Case Analysis}

Misunderstanding of concept connotation and extension or confusion of similar concepts could easily lead to conceptual errors. For example, in the investigation of "biodiversity" in question 12, wrong option "all organisms in the biosphere constitute biological diversity" took advantage of students' misunderstanding of the concept of "biodiversity".

\subsubsection{Applicatory Errors and Case Analysis}

The basic facts, principles and rules of biology need to be applied discriminatively and critically in accordance with the actual background provided by the question, and students' mechanically applying often led to applicatory errors. For example, in question 10, "ribosomes are the site of protein synthesis" is a universal law, but turns into a wrong option because of the statement of "HIV is a virus without cell structure". According to statistics, $47 \%$ of the students made mistakes because of the lack of deep thinking about the limitations.

\subsubsection{Inquiry Errors and Case Analysis}

Biology is a subject studying life phenomena and the law of life activity, which is developed gradually in the process of people's constant exploration [12]. A great portion in the examination questions involved life activities and experiments For example, question 26 was an experimental comprehensive question "to explore the optimal light intensity for the growth of a certain plant". To eliminate interference options, exploratory knowledge such as understanding of net photosynthetic rate, analysis of experimental devices, setting of controlled experiments and control of irrelevant variables should be used.

\subsection{Thinking Errors and Case Analysis}

Professor Lin Chongde of Beijing Normal University believed that the ability of any subject should be developed in students' thinking activities without which there was no subject ability to talk about. In the "Assessment Suggestions" of «the Curriculum Standards for Common High School Biology» issued by the ministry of education in 2008, traditional paper tests were also mentioned in particular: "it is not necessary to overemphasize contents requiring memorization, rather, more importance should be put to strengthen the examination of analytical and comprehensive thinking ability" [13]. Unfortunately, the interference of daily life experience, the wrong understanding of pre-scientific concept, the negative influence of thinking set and the negative transfer of knowledge give rise to students' thinking errors. For example, question 28 was based on the background of "family pedigree analysis of type I disease of certain glycogenic storage syndrome", which required students to skillfully apply the understanding of the hereditary mode of genetic diseases and reasoning according to the genealogy. Judging from statistics, this question resulted in score loss rate as high as up to $48 \%$. Therefore, this kind of questions with higher requirements on thinking quality were quite difficult for students.

In addition to the aformentioned common classification of student errors, errors could also be classified into individual errors and group errors according to the score rate of each question obtained from big data. If group errors were found, teachers should not simply put the students to blame, but should reflect on whether the design and implementation of their daily teaching activities were based on Zone of Proximal Development, whether the teaching objectives had been well achieved, or whether the proposition of the difficulty of the test was reasonable. For example, question 22, concerning "activity: the study of meiosis model", had scoring rate of only 0.38 . Close analysis revealed that some teachers did not pay enough attention to or even ignored the operation of model experiments in their daily teaching. This kind of errors were teacher-caused and also worth our attention.

\section{Customized Error Solving Strategies for Students}

First of all, teachers should accept the fact that "what is actual is rational" as far as possible in order to create a relaxed and harmonious atmosphere. To accept the students' errors is to keep open a communication channel for students to discuss the errors. In addition, teachers should judge, screen, sort out and refine these errors tactfully, and make efforts to design targeted and tailored solutions. Students may make a variety of mistakes of diverse types or natures; therefore, teachers should deal with them with different priorities and methods.

\subsection{Solutions to Reviewing Errors}

Strong ability to review questions demands big knowledge reservior, good reading habits, and effective thinking methods. Teachers could provide some question review skills for students with weak reviewing ability step by step: 1) to analyze prompts and figure out solutions. Take question 27 as an example. It provided a schematic diagram of 3 kinds of meter pointer deflections. If students could utilize knowledge of potentiometric analysis, then they could conclude with great ease that the first kind was impossible, eliminating 2 wrong options immediately. 2) to filter out key elements and identify traps. Find out and mark key words (including core concepts and qualifiers, etc.) in the question prompts. Questions with lack of information, information redundancy and hidden conditions deserve a lot more attention because 
they may have traps hidden in them. 3) Combine various methods to overcome the thinking set. Some more difficult biological questions may have comparetively more qualifications and data, and thus creating difficulty for test takers in making sure of the relations between conditions. This essay suggested that students can think out of the "frame model", try to classify, sifting simple and basic principles out of labyrinth of conditions, reverse thinking among a variety of methods.

The improvement of the reviewing ability could never be achieved overnight. It needs a long-term process of learning, accumulation, reflection, consolidation and development.

\subsection{Solutions to Knowledge Errors}

Many teachers were used to making direct correction and informing students of the correct answer whenever they take notice of errors in students. This way of handling errors seemed to be less time consuming and efficient, but the repeated occurance of one's mistakes was common indicating that teachers failed to help students find the root causes of the errors.

"What went wrong" and "why" were two aspects that teachers must pay close attention to when correcting errors [14]. The former reflected the problems students had in the process of learning, which was an external symptom. The latter reflected the cause of students' learning problems, which belonged to internal pathology. Teachers should guide, encourage and provide opportunities for students to strengthen self-reflection, categorization, integration and optimization of knowledge when coping with conceptual errors, applicatory errors and inquiry errors. This was not only conducive to fundamentally solving knowledge errors, but also to students mastering scientific learning methods in the process of thinking and solving problems, forming and improving independent learning, and inspiring students to overcome difficulties and experiencing the sense of accomplishment after solving problems.

\subsection{Solutions to Thinking Errors}

Through observing learners and the mistakes they made, American scholars Erlwanger, Ashlock, Ginsburg et al., found that many errors were not accidental or taught by others, but resulted from learners constructing their own unique concepts and programs [15]. Although people's thinking activities always go on silently, but teachers could encourage students of different levels discuss their errors. In such an explicit way, some students could recognize what went wrong in terms of methods and strategies in solving problems, while others drew upon from their classmates and teachers' experiences and lessons.

"There is no mathematician who had not miscalculated." According to the analysis of group errors, we know that part of the problem may lie in teachers themselves. If it was indeed a teacher's fault, be sure to calm down, make timely analysis and judgment, and adjustment and take remedial measures, so that the teacher-caused errors became a rare and precious opportunity to consolidate subject knowledge and develop students' thinking. "Be not ashamed of mistakes and thus make them crimes" is an old Chinese saying. It means how ideally teachers should treat wrong bebaviors could also become an exemplary model for students to follow when they handle errors.

In addition to strengthening learning, teachers should also develop a good habit of solving test problems themselves. Only by doing this can they have a deep understanding of various types of students' errors.

\section{Conclusion}

The more specific and detailed the teacher's analysis of the errors was, the stronger their ability to harness the error resource and on-the-spot control willed be, and thus the better the effect of errors utilization willed become. this essay divided the common errors students made in biology exam into three types: reviewing errors, knowledge errors and thinking errors. And the knowledge errors were divided into conceptual errors, applicatory errors and inquiry errors.

some students may make mistakes in reviewing the questions due to their haste in completing the questions, distortion in extracting the main information, insufficient exploration of the hidden conditions, and falling into the trap of interfering options. Teachers could provide some question review skills for students with weak reviewing ability step by step: 1) to analyze prompts and figure out solutions. 2) to filter out key elements and identify traps. Find out and mark key words (including core concepts and qualifiers, etc.) in the question prompts. 3) Combine various methods to overcome the thinking set.

The students' lack of knowledge in biology was the main cause of their mistakes. Knowledge errors could be further divided into several subtypes: Misunderstanding of concept connotation and extension or confusion of similar concepts could easily lead to conceptual errors. The basic facts, principles and rules of biology need to be applied discriminatively and critically in accordance with the actual background provided by the question, and students' mechanically applying often led to applicatory errors. A great portion in the examination questions involved life activities and experiments. They would lead to inquiry errors for lack of analysis of experimental devices, setting of controlled experiments and control of irrelevant variables. Teachers should guide, encourage and provide opportunities for students to strengthen self-reflection, categorization, integration and optimization of knowledge when coping with conceptual errors, applicatory errors and inquiry errors.

The interference of daily life experience, the wrong understanding of pre-scientific concept, the negative influence of thinking set and the negative transfer of knowledge give rise to students' thinking errors. Teachers could encourage students of different levels discuss their errors. In such an explicit way, some students could recognize what went wrong in terms of methods and strategies in solving problems, while others drew upon from their classmates and teachers' 
experiences and lessons.

In addition to strengthening learning, teachers should also develop a good habit of solving test problems themselves. Only by doing this can they have a deep understanding of various types of students' errors.

\section{References}

[1] Zhu xiaoman, "New encyclopedia of Chinese teachers," Beijing: China encyclopedia press, 2002, pp. 484.

[2] Ye LAN, "New Basic Education" -- exploration and understanding of school reform in contemporary China, Beijing: education science press, 2006, pp. 56.

[3] Ministry of Education, PRC, "the Curriculum Standards for Common High School Biology (2017 edition)," Beijing: people's education press, 2017.

[4] Hua yinglong, "Listening to the real voice of children's thinking: my Resource utilization of errors education concept," vol. 2. People's education, 2010, pp. 43-46.

[5] Zhang kangkang, hu yangyang, The way of science teaching in China to get out of the thought of "question sea tactics". vol. 36 (02). Educational theory and practice, 2016, pp. 57-59.

[6] Wang ruiqin. Some understandings on effective teaching of high school biology. vol. 11. China external education, 2018, pp. 129 .
[7] Teng jingjing, "Analysis of metabolic learning isomerism in senior high school," jinan: Shandong Normal University.

[8] Wang jinfa, "Cell biology," Beijing: science press, 2003, pp. 5-7.

[9] Yu han. Never forget the original intention to promote the reform of the New College Entrance Examination. vol. 3. Higher education research in China, 2018, pp. 17-23.

[10] Shao danwei. Middle school science examination, vol. 2, 2005, pp. 51-52.

[11] Zhejiang education examination institute. "Zhejiang province general high school achievement level examination and college entrance examination standard.," Hangzhou: Zhejiang photography press, 2016, pp. 129.

[12] (U.S.A.) Alton Biggs, etc. Editor, Translated by Liao sumei etc., "Discoverer of science: Biology-The Dynamics of Life," Hangzhou: zhejiang education press, 2008, pp. 26.

[13] Ministry of Education, PRC, "the Curriculum Standards for Common High School Biology (experiments)," Beijing: people's education press, 2003, pp. 43-44.

[14] Liang yanying. Case analysis of management strategy of wrong questions in high school biology under metacognitive monitoring theory. vol. 8. Biology teaching in high school, 2018, pp. 2-33.

[15] (UK) Paul Ernest. Translated by qi jianhua, "Philosophy of mathematics education," Shanghai: Shanghai education press, 1998. 